\title{
COVID-19 upon Us: The Work-Family Experiences of Married Couples during the First Three Months of the Pandemic in Lagos, Nigeria
}

\author{
Victor Ibrahim Kolo, Charles Osezua, Gloria Osezua, Charles Aigbona \\ Institute for Work and Family Integration, Lagos, Nigeria \\ Email: victor.kolo@iwfionline.org
}

How to cite this paper: Kolo, V. I., Osezua, C., Osezua, G., \& Aigbona, C. (2021). COVID-19 upon Us: The Work-Family Experiences of Married Couples during the First Three Months of the Pandemic in Lagos, Nigeria. Open Journal of Social Sciences, 9, 1-21.

https://doi.org/10.4236/jss.2021.910001

Received: July 21, 2021

Accepted: September 26, 2021

Published: September 29, 2021

Copyright $\odot 2021$ by author(s) and Scientific Research Publishing Inc. This work is licensed under the Creative Commons Attribution International License (CC BY 4.0).

http://creativecommons.org/licenses/by/4.0/

\begin{abstract}
The Corona Virus Disease of 2019 (COVID-19) produced enormous impact on work and family across every sector of life. In order to contain the spread of the disease which occurred with great rapidity, both workplaces and families were globally forced to shut down from public engagement. Lagos, being the epicenter of the disease in Nigeria, was more hit by the impact of the pandemic, amidst great fears and anxiety, in spite of the busy nature of socio-economic life in the mega city. This study explored couples' experiences and coping strategies as they negotiated the "emergency normal" that confronted them during the first three months of the lockdown. Using interpretive approach, In-depth Interviews were conducted with ten (10) couples, comprising five (5) males and 5 females, with marriage life ranging between four (4) to ten years and drawn from across various occupational sectors of the Nigerian society. We investigated couples' experience of the lockdown using a tripod of approaches: pre-COVID-19 lockdown, COVID-19 lockdown and the futuristic approach of the post-COVID-19 period, all based on couples' experiences. We found that work-life integration, desirable as it is, seemed difficult to practice in Lagos. Beyond the conventional work-life integration (WLI) approaches to and strategies for WLI, there is need to develop more practicable frameworks that can enhance WLI practice, based on the peculiar situation of married couples in Lagos, Nigeria.
\end{abstract}

\section{Keywords}

COVID-19, Work-Family Life, Couples, Relationship, Lockdown 


\section{Introduction}

The outbreak of the Coronavirus disease of 2019 (COVID-19) overwhelmed work-family interfaces across national and global contexts. The pandemic provoked comprehensive impacts on every sphere of human endeavour, and at all levels across the globe: regions, states, communities, households and individuals, without exempting the dynamics of work-family interface. The impact of COVID-19, indeed, has transformed the experience of work-family life for all, particularly working couples whose family life seems to confront a forced re-integration amidst the COVID-19. Thus, leaving both individual and intimate as well as family relationships in great challenge and negative effects (Stanley and Markman, 2020), not neglecting its positive effects on future interactions (Rivett, 2020). Due to its sensitivity to the human world, studies related to family life are today regarded as the most widespread social experiment of all time (Lebow, 2020). This has motivated the Institute for Work and Family Integration (IWFI) to investigate the experiences of COVID-19 among working married couples in Lagos state, Nigeria.

\section{Method}

The study adopted the exploratory design and utilised in-depth interviews (IDI) in eliciting qualitative data from 10 participants. The participants were conveniently selected from among couples who had participated in IWFI's Marriage Couples' Relationship (MCR) Programme in Lagos, Nigeria. These participants were purposively called on the phone, for consent to voluntarily participate in the study. The choice of Lagos for this study was because the city is Nigeria's commercial nerve centre and busiest city, as well as the epicenter of COVID-19 pandemic in Nigeria. Additionally, Lagos had one of the longest and strictest lockdown episodes in the country. Selected couples, comprising 5 males and 5 females belonged to various socio-demographic categories which provided a strong basis for appropriating robust data from a diverse spectrum of subjects, in line with the predetermined IDI guide which served as instrument for the study. These couples who, among others, agreed to participate in the study, constituted the interviewees. Data was, therefore, collected through telephone interview methods, with the aid of a predetermined interview guide and probing techniques where necessary. Data was transcribed and thematically analysed and inferences drawn to vividly describe couples' views of the complexity of work-family life interface before, during and after the novel coronavirus pandemic.

\section{Discussion of Findings}

\section{Socio-Demographic Attributes of Study Participants}

Socio-demographic attributes determine the nature of peoples' personal life, their family, work and the associated intersections. They also provide information about people's tendency and functionality across the social spheres of inter- 
est providing bases for proper understanding inference about behaviour. Socio-demographic characteristics play important roles as major determinants of work-life experience and life outcomes of working couples. They also serve as basis for scientific inferences regarding the subject of focus. Table 1 presents a summary of socio-demographic attributes of the work-family interface of the subjects of this study.

As can be observed from Table 1, respondents comprised five married men and married women with marriage experience ranging between 4 years and 20 years while majority of study participants' families were dual-earner. That is, participants and their spouses were both fully and directly involved in socio-economic occupations where they work full time and earn income. Like the findings of previous studies (Kasa and Hassan, 2017), this also implied that the stress and strains occasioned by "work" could have dual impact on the participants family. For instance, both couples were likely to suffer fatigue (and its spill-over effects) by the end of the day's work. This has implications for burnout, related health and other socio-economic aspects of peoples' life. The situation may be accentuated by the peculiarity of Lagos-a mega city with high stress and strains emanating from the difficult commuting traffic with attendant impact on productivity.

\section{Work-Family Life Prior to COVID-19}

Prior to the outbreak of the COVID-19 pandemic, the study participants had evolved a pattern of life in line with the reality of their city of residence. They had a way of life, work, inter-spousal and familial relationship that saw them through the everyday life. In line with bio-cultural adaptation tenets, such patterns are evolved, over time, to facilitate easy negotiation of the challenges of everyday life. All of the respondents reported a positively healthy relationship with their spouses, which according to them, they valued very highly. One participant reported:

Table 1. Socio-demographic characteristics of respondents.

\begin{tabular}{ccccc}
\hline $\begin{array}{c}\text { Interview } \\
\text { Participant }\end{array}$ & Sex & $\begin{array}{c}\text { Years of } \\
\text { marriage }\end{array}$ & $\begin{array}{c}\text { Occupation } \\
\text { and sector }\end{array}$ & $\begin{array}{c}\text { Spouse's occupational, } \\
\text { if working }\end{array}$ \\
\hline 1 & Female & 10 & Copy writer & $\begin{array}{c}\text { Nursery and Primary school } \\
\text { Teacher }\end{array}$ \\
3 & Female & 20 & Entrepreneur & Entrepreneur \\
4 & Female & 7 & Media & Entrepreneur \\
5 & Male & 13 & Information Technology & Real estate \\
6 & Male & 6 & Oil and Gas services & Pharmaceuticals \\
7 & Female & 1 & Educational Administration & Educational Administration \\
8 & Male & 6 & Secondary School Teacher & No \\
9 & Female & 12 & Oil and Gas services & No \\
10 & Male & 5 & Ond Company & Banking Sector \\
& & & ICT & Non-profit \\
\hline
\end{tabular}


I ve always had a fantastic relationship with my spouse. I $m$ the kind of person that put family ahead of all. Like I said, just after my work, is the family unless I have any other place to be of course that will also have to be something that will benefit the family or my spiritual growth and then having attended family advisory system, that opened my eye more to the family. (Husband, Secondary school Teacher, 7 Years of marriage).

The response above also implicated the role of formative programmes like the family advisory system, in enabling couples to better realize the dignity of family life and the need for each to develop quality relationships with their spouse. Quality relationship with one's spouse is closely linked with the tendency to spend time together to advance the marital friendship, a major factor for a flourishing marriage and family life. Thus, another participant remarked

Although we do not yet have children of our own, my spouse and I have excellent relationship. We realise the need to keep going and enriching our relationship, and that is why we make out time to get-together at least 3 hrs each day (Husband, Secondary school Teacher, 10 Years of marriage).

However, the demands of work tend to threaten marital friendship between couples, by limiting the amount of time available for rejuvenating marital relationships, regardless of employment status. Thus, the impact of external stressors on family life especially couples' romantic relationship cannot be denied. In fact, studies have continually shown that demanding jobs, economic hardship and disasters threaten couples' marital bliss (Pietromonaco and Overall, 2020). To ensure maintenance of stable and quality relationships, couples must be sensitive to the dangers that could undermine its attainment. According to one participant,

We (participant and spouse) used to work 24 hours at the beginning of our marriage. We are spending more quality time now. The first one or two years was not the way our marriage is now... In the past two years we have been able to dial back and with our son growing and becoming more aware and asking questions you find out that I need to spend more time with him and things like that. (Husband, Entrepreneur, 20 Years of marriage).

While this suggests the imminence of work-family conflict due to the demands of today's everyday life, not every couple may have the opportunity of an increased time for family life as they progress in career. This, additionally, vests responsibility on couples to be sensitive to the needs of their family, especially with regard to inter-spousal relationships and the parenting needs. For it has been discovered that when couples allow themselves to be overwhelmed and distracted by work, they tend to become inadequate with family responsibility, blame their partner unnecessarily, provide poorer support and, are soon faced with the danger of becoming less satisfied with their partner and relationship. Insensitivity to the imminent danger posed by lack of family cordiality, is responsible for the unhealthy negligence of the importance of family friendship. As can be observed in the above excerpt, the participant realized the need to spend more time with his child as he (the child) grew up and began to ask ques- 
tions.

Corroborating this, another participant noted that long working hours which sometimes spilled into the weekend reduces the opportunity that they have to spend quality time together. Even when he returns from work, he is unable to make out time exclusively for family, due to distractions of the workplace:

The demands of work impact adversely on my family life. I work late and come back home around $9 \mathrm{pm}$. Sometimes I work on the weekends even when I come back there are jobs that would be on my mind. (Husband, Secondary Teacher, 10 Years of marriage).

Thus, there is an inherent tension in the work-family dynamic, especially among residents of a mega city like Lagos. Fatigue arising from work and daily activities are brought home. Owing to the consequences of such fatigue, the family life is greatly affected. For such condition is capable of affecting couples' relationship as it will determine the nature and extent of interaction as well as perception partners have of themselves. The arising tension if not properly managed, will not only affect inter-spousal relationships, but will have far reaching implications for parenting, family-life outcomes and the quality of citizens in a country. Thus, spouses must show concern and sensitivity to their partner's changes both physical and psychological for a worthwhile experience of the family life. Foregrounding this, a participant further noted that the only way in which work has been affecting his family is in the area of parenting. According to him,

The fact that when I $m$ not there, I don't have a help and my wife alone is left with the kids. We have three kids and of course the work she does if I am available, we could have done them together ... So, I cannot say that I am daily involved in the life of my children, but I try my best whenever I am available, especially on weekends. (Husband, Secondary Teacher, 10 Years of marriage).

Furthermore, most of the participants could also not make out time, deliberately, to hang out with their spouses. This spells danger to couples romantic and intimate relationship. In an increasingly busy society with its own stress and strain amidst a generally infrastructural environment, there is the need to ease out accumulated pressure and from time to time, rejuvenate bliss in the family. The role of family time in relaxed niches, outside of the domestic environment has proven to have refreshing and recreational impacts on families. Such time shared with family provides the necessary support family members require to stay emotionally and socially competent in different spheres of life, especially for children (Osofsky and Fitzgerald, 2000). Through this means, couples renew their love and strengthen the marital bond that holds them together.

Evidence from the foregoing suggests that prior to the COVID-19-induced lockdown in Nigeria, couples' everyday life tends to undermine the opportunities for a flourishing marriage and family life with the desired outcomes. Given the place of family as the bedrock upon which rests society as a whole, there is 
the need to support couples and families to be able to enjoy happiness while contributing to nation-building, reproducing the society and nurturing responsible citizens. As may have been observed, couples cannot achieve this on their own. There is the need for government to provide national ambience through infrastructure and facilities that enhance the peoples' quality of life. There is also the need for employers to better engage their workers for improved productivity without having this take the toll on marriage and family life of employees. Similarly, the married couples also need to carefully study and understand the uniqueness of their family and spouses vis-à-vis the peculiarity of their work-family situation and the nature of demand in both ends.

In Nigeria and most other African climes, marital stability and happiness which determine a lot about workplace productivity with far reaching implications for national income, has not been accorded adequate attention. Family outcomes have been left to be determined by societal culture and tradition without conscious and deliberate efforts on the part of stakeholders such as policy makers, employers, managers and couples themselves. This necessitates sensitization, advocacy and intervention for the end of assisting married couples, as husbands and wives, parents, employees and members of society who play important but unrecognized roles of societal regenerators in all their spheres of endeavour. This is important in order to enhance happiness and optimum productivity for the good of all.

Given the complexity of today's life in a mega city like Lagos, there is the need to build employees' capacity to harmonize the work-family spheres of their lives. Organisations have a critical role to play in equipping their workers with the skills to master the art of work-life integration, through training, while also adopting family-friendly policies for better employee engagement, improved productivity and job satisfaction (Organisation for Economic Co-operation and Development, OECD, 2008). The necessity for such family-friendly policies needed for effective work-family integration was greatly exposed during the period of lockdown.

\section{Work-Family Life during COVID-19}

The lockdown occasioned by the COVID-19 pandemic altered the existing pattern of everyday life in families and workplaces, with great impact on the relationship between spouses, their children, other family members as well as colleagues and the organisation of work. People were confined to their homes, and the regular socio-economic activities of their everyday life was either reduced or totally denied them. Thus, the COVID-19 pandemic has had and continues to have far reaching impact for both work and family now and in the future. For many families, this period marked the very first time that they would be spending prolong times together as a social unit.

Table 2 presents the specific impact that the COVID-19 pandemic has had on participants, due to the lockdown. As would be expected, these different dimensions of impact generated various forms of stress and anxiety in participants. 
Table 2. Participant-reported specific impact of the lockdown.
1) Irregular wake-up times
2) Lack of convenient workplace ambience in the house
3) Inability physically attend religious congregations
4) More time for spiritual development
5) Virtual schools for the children
6) Review of shopping/home-stocking schedules
7) Inability to visit loved ones
8) Boredom
9) Change in work-sleep-leisure time ratio
10) More time for play, reading indoor games
11) Suspension of weekend activities
12) Greater need and more time to clean the house
13) Having to assume the role of school teachers for the child(ren)
14) Limited time for actual work

As can be observed in various submissions by participants, there was a major challenge of adaptation due to the rapidity with which their accustomed reality was being swept away, and swiftly replaced by a new order associated with uncertainty and unpredictability. As most members of the family were forced to share large part of their time together at home, which is very unusual or occasional in time past. In many ways the dynamics and behavior of the family has had to change (Osofsky and Fitzgerald, 2000). This constituted the major cause of frustration among participants who mostly did not understand the strategies for adapting to the new reality imminently confronting them. According to one participant who has realized the need to adjust,

We used to go for shopping and do some restocking every 2 weeks. But now with the advent of this stay at home policy where we have to go and buy things in bulk and just managing so all of those dynamics have to change and some things that we used to do we just had to adjust because of this stay at home policy. So, we have done a lot of this adjustment in every area especially going out. Times have really changed and we need to see how to work some things out. (Husband, Oil and Gas service, 4 years of marriage)

This forced adjustment has placed enormous pressure on parents in making sure that their home enjoys basic amenities provided by government which they are billed for. The stay at home policy caused an increased rate of consumption of these essential amenities, which means extra expense for the spouses especially the bread winner in single earner families. Amidst this uncertainty, spouses scrupled with making certain essential needs available at home and the challenge of managing such resources as there was no certain date of return to normal life. Thus, a respondent noted a major challenge was management of resources:

We are doing our best to pull out all the studs. It has been quite challenging and stressful. Having to manage resources especially now that we are at home the pressure to manage the consumption of whatever we have at home like elec- 
tricity, water supplies and all that because we can't go out to restock. (Husband, Copy writer, 10 years of marriage)

The management of consumptions as well as increased demand on childcare have brought about family tensions. For to ensure availability of the above basic home necessities, couples endure some form of economic pressure. Such economic pressure mixed with uncertainties of employment have been discovered to heighten individuals stress during the coronavirus (COVID-19) pandemic (American Psychological Association, 2020). In the midst of this is a goal to meet demands of work where the lockdown has not reduced work expectations. In fact, the expectations and work demands have in some cases increased, making the stay at home to be a little short of relaxation as it evoked fear and anxiety amidst uncertainty in a time of scarce resources. There were psychological dysfunction such as anxiety and depression (Ojewale, 2020), which when improperly managed, could generate frustration and aggression, including self-harm and suicide. Owing to this, couples' relationship and interaction during COVID-19 pandemic was accentuated by both economic and mental stressors. As spending quality time with family was important, so were the resource to ensure a happy life. Therefore, the lockdown came with a twist that complicated family wellness.

The lockdown left many employers and employees with the challenge of staying alive and active through the remote work policy. This hindered the work-life as the family life demanded even more during the lockdown, a situation that constituted enormous challenge to workplace productivity. Spouses battled through meeting up with increased domestic needs and care for their wards and partners in addition to the demands of work. Apart from meeting domestic needs, there was also the assumption of teaching roles by spouse owing to the closure of schools. This new role complicated activities within the home especially for couples living alone with their children without support from an older figure that could help care for the kids. This lack of childcare (e.g. day care and school) was a major external stressor that affected couples mentally during the covid-19 pandemic (Pietromonaco and Overall, 2020). The demands of educating the child further compounded participants' effectiveness while working from home. This was because the responsible institution were now unable to engage the children as directly as they used to, thereby forcing parents to assume such responsibilities in addition to workplace deliverables. This generated exhaustion which further impeded participants' efficiency and effectiveness. A respondent stated that,

Before the pandemic, we were told to work from home but after the pandemic we were told to remain in business and make sure everybody still works from home. ... it is quit tasking, very difficult having to teach the children. Then use most of the day cooking, cleaning and online schooling. Very little time is done for actual work. (Husband, Information Technology, 13 years of marriage)

This submission corroborates the prediction of United Nations Office for Drug and Crime (UNODC, 2020), that many parents would find it stressful to 
balance work, caring for children, and maintaining the household, particularly when separated from their regular support networks. The challenge of trying to manage activities and demands of work-family life in a domestic environment has been discovered by this study to constrain spouses. Respondents alluded that meeting up with the demands of essential domestic services like the above stated and still giving one hundred percent to work while at home may not be easily achieved. The distraction from children cannot be ignored and proper supervision of work activities by managers is also hindered. Basically, without the children at home, working from home could have been easier, other things being equal. A respondent who did not see working at home as a serious issue because it was part of his work schedule previously, however decried the distraction he suffers from family while working during the lockdown, saying;

Nothing has changed. I am still working. The directive has nothing to do with my employer. My schedule is still the same, so nothing has changed. Just that, I have a four-year-old that is always dragging my laptop with me. Without the distractions from my daughter, I am fine. (Husband, ICT, 5 years of marriage)

This meant that significant others who are now forced to stay at home also constituted possible sources of distraction to effective remote work. Another respondent who felt prepared because activities were put in place to help handle the changes in work, could not help it but complain that the experience brought about a mixed feeling. For him, it was good having family around for longer hours than the usual, where relaxation together was only possible during the late evenings after everyone must have returned from specific duties. While the sad part was having to manage the distraction posed by virtue of family presence all through the day while he carried out job task as usual. For the respondent, job schedule may have not been altered, but the atmosphere and environment, though same home, had changed because of the presence of family especially the children. Thus, effectiveness was no longer guaranteed.

We (his organization) are observing it and the activities are designed to make it work. But $1 \mathrm{~m}$ not effectively working from home. The children are also at home. The experience has been bitter and sweet at the same time. Teaching children. Most of the day cooking, cleaning and online schooling. Very little time is done for actual work. (Husband, Information Technology, 13 years of marriage)

It is implied, therefore, that children could constitute a major source of distraction and hindrance to the effectiveness of the work from home policy. As the attention of spouses are grossly divided; attending to work demands as well as the sensitive needs of their children and partner. To tackle this challenge, spouses may need to provide themselves an official working space in the home in other to reduce drastically distractions arising from child(ren) care. This will be an effective way of bringing about focus and necessary workplace ambience needed for effectiveness in meeting work demands. According to a respondent,

when we need to balance work and family life there are plenty of distractions that go with it. Maybe because my house is small, and I don't have a space maybe 
for those who have bigger houses and a special study room where you can do some work and your kids, you'll be able to attend to them and all that. So, there are a lot of distractions that go with it. Maybe if I were to be a bachelor maybe I would have been coping better so some distractions really go with it. (Husband, Oil and Gas service, 4 years of marriage)

Such approach will enable spouses shuffle through the responsibilities, helping them manage less stressfully the demands from work and family while staying home. This is in line with the suggested coping skill recommended by (UNODC, 2020) that admonish spouses to look after themselves as much as possible by sharing childcare responsibilities with other adults within the home, setting aside time for themselves to work or rest, and maintenance of routines when possible. Adherence to these coping skills will go a long way in ensuring spouses stay alive and active while staying home. And productivity would not be hindered as reported except if the needed resources/infrastructure needed to stay connected to work are not made available.

In view of this, participants in this study reported the challenge of having a reliable internet system to help them stay connected with their organizational team. Availability of quality and reliable network/internet connectivity would keep spouses constantly in touch with their respective work and needed family interaction. For the importance of communication while working from home in a time of lockdown and where social gatherings and visitations are restricted, is undebatable. Such communication cuts across employers and employees; service providers and consumers including schools (teachers) and students (children of these parents) and between family members/relatives. Thus, the reaction/ comment:

Internet connectivity is the basic thing. This period, managers need to be more empathic and need to be more patient because the internet situation in my country is not as fast. When they are having a meeting, they need to be patient because there would be interference in terms of the network. Things will not move as fast as you want. (Husband, Oil and Gas service, 6 years of marriage)

The danger of not having a fast and reliable internet service within the home during the lockdown cannot be overemphasized. Such condition proved injurious to both work and family life expectations. It made it difficult to assess family members wellness, slowed down work progression and hindered some personnel from participating actively in important deliberations and activities of work. As a result of this, respondents reported getting more than one internet service provider to ensure they stayed active online. Helping them stay in contact with other family members and the schedules of work. Thus, the statement,

Everything can be one hundred percent done from home. The barrier of working from home is mainly power supply and internet. These are the major things. For internet I use more than one service provider so that takes care of fluctuation issues or slow network. (Husband, ICT, 5 years of marriage)

However, the cost of utilizing more than one service provider for internet ser- 
vice has great implications on family economics. But then, such service is also needed to connect to family members from far and wide. To keep close contact with family members as visitation was suspended meant a greater need to communicate not just in voice but also physically through video. Rivett (2020) highlighted how online platforms like skype and zoom were deployed to keep close contact with family members and significant others. None of the study participants complained of inability to communicate with their spouse, since they all had their spouses around. They, however, complained about inability to maintain usual routine visits to other family members. According to one,

Our family life and routine have been altered. We can't hang out, go to church or visit family members. All we do is read and play indoor games, which creates conducive environment for jokes. We create avenues for jokes as well as develop better prayer life and games for better bonding within the family. (Wife, Gas company External Relations Officer, 12 years of marriage)

This shows some of the coping skills that families deployed in living happily through the lockdown. Despite the inability to hang out, participants with their families created avenues for development of deeper senses of love. This, however, seemed not to meet the total needs of couples and their family. Issues pertaining to faith needed a closer and more valid connective channel for its efficacy. In view of this, couples did not have adequate internet connection and power supply to meet their spiritual needs virtually. Aside keeping apace with work demands, staying spiritually connected in matters of faith and for continuous educational development required enormous internet connectivity and power supply resources during the lockdown. Thus, resources needed to be allocated for these, in view of the generally epileptic state of electricity in Nigeria. A respondent lamented this challenge stating:

They advised us to work from home. I work from home but lack the needed resources to do so effectively, as internet subscription and power supply are very essential necessity. We can't attend Sunday Masses except we do it online. The children also have to school online as well. (Wife, Educational Administrator,

\section{1 year of marriage)}

The need to stay connected online for various purposes was more pressing during the lockdown. It was necessary to know exactly what was going on around one's society and the globe at large while at the same time pursuing the normal daily activities from home. Staying connected promotes healthy and productive work-family life (UNODC, 2020). Hence, it was difficult to overlook the channels that could help such connectivity despite its financial costs. It is, therefore, better imagined, how tough the lockdown would have been for financially-constrained spouses who worked from home. There was the struggle with stocking the home with food, managing resources, ensuring availability of power and water supply, having internet connection to stay active online and caring for the child(ren), all of which took economic toll on participants.

Despite the demands, couples still had essential roles to play in deciding the 
fate of their family as regards the effect of the pandemic. Pietromonaco and Overall (2020) revealed that the nature of mutual engagement between couples was a predictor of the intensity of external stress arising from COVID-19 pandemic will have on family life. This means that lack of understanding among couples could accentuate the effect of the external stress due to the pandemic, with great impact on their family life. Conversely, couples who enjoyed good understanding among themselves, stood the chance of overcoming the external stress, and thus preserved family bond, peace and solidarity.

Preservation of family bond and friendship requires genuine atmosphere of love and a feeling of togetherness (Osofsky and Fitzgerald, 2000). These helps to build a positive perception within the family. An individual's perception of other family members goes a long way in determining the nature of interaction and cordiality inherent. When couples develop positive perception of each other, their understanding is bound to increase as well as the desire to succeed as a family regardless of the challenge. However, the busy economic activities couples engaged in, may not have given them room to develop positive perception of each other, prior to the lockdown. They come home late and tired most of the time and still use some hours of their weekend to complete work tasks. To such couples, the lockdown experience was a blessing. A respondent confessed to experiencing family in a new atmosphere/ mode which he had missed for long, due to the demands of work prior to the COVID-19 lockdown. According to the respondent,

Observing the children in their natural habitat, putting the children in a school mode and seeing my spouse in a non-work mode, not in an exhaustive state, and all these over a prolong time, running into months were both amazing and refreshing. (Husband, Information Technology, 13 years of marriage)

Thus, we may conclude that the respondent only shared limited time with family prior to the pandemic which had deprived him from enjoying the warmth of family. Such deprivation and distance from family no matter the reason only spells danger to the joy of marital bliss. It increases the gap between spouses as well as their children hindering transmission of sacrosanct values through generations. In light of this, a respondent who had been guilty of distancing self from family due to work demands confessed to the positive effect the lockdown had on him and his family. Though shares six hours daily with the family but, effective time of interaction was limited. The respondent noted that the lockdown afforded him the opportunity to share valuable time with his children. This were, he was able to transmit some cultural knowledge to the children while making up for the lost opportunities of previous times. Thus, he stated

I have missed teaching the children their local language. So, I realized the need to do so during this period (that is, the time of lockdown). And this has become a routine practice. One of the problems we have in our society today is due to the cultural orientation of children (Husband, Secondary school teacher, 6 years of marriage) 
This affirms that the period of lockdown had been beneficial to spouses in terms of appreciation of the real personality of each other with less complication from external variables such as stress and work-family conflict. Getting to share quality time with children may not have made spouses appreciate the nature of work done on childcare by the spouse or service provider but, also ensures the well-being of the child(ren). Children's proper well-being depends not only on nutritional and medical care, but also on proper parental companionship (Ghosh, Dubey, Chatterjee and Dubey, 2020). Such disposition brings about enjoyment of love and happiness, creating avenue for jokes and better family bonding. Realization of these facts in the family-work life could only help spouses appreciate the lockdown experience. Owing to this, a respondent confessed to have enjoyed the lockdown because it provided an avenue for "great bonding and better knowledge of family members.

Respondents seemed to have, in many cases, stayed apart from their partners prior to the lockdown due to work demands. The respondent who had lived apart from her spouse for many years due to demands of work felt she lacked sufficient bond with her family and had a lot to learn. For her, the lockdown became a means to rekindle family love which she has come to appreciate. While another respondent reported a bitter-sweet experience and struggle with managing the children interruptions while working, she on her part enjoyed a journey of rediscovery of family warmth which will surely have a long-lasting effect on her future decisions as regards family. Thus, spouses need to look at the lockdown experience as regards work-family life in a positive light irrespective of the challenges.

As challenges are bound to occur in every sphere of the human life, so too, coping strategies are evolved, during or after occurrence of such challenges are required to manage appropriately every situation. Respondents had intriguing strategies that working spouses could consider in situations of lockdown, that will ensure their effectiveness while working from home. Notable among the suggestions made was that of a respondent whose contribution exposed the usual family-life demands faced by spouses as well as coping strategies that could be most helpful for productivity in work-family life situation.

Mostly work interruptions from the children. A lack of work structure, Irregular wake up time. For now, there's no structures convenient for work. Major challenge was, wake up in the morning, attend to things that need attention from work. Clean the house. Sort the children, prepare their breakfast, and work on other things that need to be worked on. (Wife, Oil and Gas service, 6 years of marriage)

This foregrounds the complexity of family life demands in the face of work pleasure. A system or life pattern that is never fixed and almost impossible to predict. Meaning that couples attend to domestic needs as they arise though, some could be postponed. However, it is clear that couples hardly have time to rest from domestic chore when home and especially when there are kids around. 
To manage such complications, couples and other adults need to develop a format that would help tackle the challenge. Thus, a respondent stated the necessity of following a structured program or system while working from home in other to meet the dual demands of work and family life. The respondent proposed the below.

When we need to balance work and family life there are plenty of distractions that go with it. Maybe if I were to be a bachelor maybe I would have been coping better so some distractions really go with it. Maybe because my house is small, and I don't have a space maybe for those who have bigger houses and a special study room where you can do some work and your kids, you'll be able to attend to them and all that. (Husband, Oil and Gas service, 4 years of marriage)

This implicates the need for a make-shift office within the home, to afford the workplace ambience needed for carrying out official work. This would make for a very little distraction and remarkable level of productivity. Spouses would better respect each other's workspace while their children grow up with a positive mind towards work and family life integration. Other family members would, similarly, become sensitive to the structure put in place which will ensure better focus and productivity for all. Such impact from family is bound to have a long-lasting effect on couples, children, and the general society.

Therefore, given the centrality of family to individual and societal stability in an age of declining family values, there is the need for deliberate intervention in support of the family institution. Organisations need to be sensitive to the role family plays in development of society. Importantly, the government need establish a policy that will be family-work friendly for a sustainable moral society. A policy that would address work and family life conflicts. With this in place, couples would come to enjoy maximum support that would transcend into work productivity for the general good of society.

\section{Work-Family Life: Lessons for the future}

Work and family life are indeed intertwined, each important and unique in their own rite. None should be considered more valuable or prioritized over the other. Building a lovely home is as important as having a successful career, and both aggregate to produce happiness of life. Thus, the work-family interface is complex and requires attention as it also has great consequences for the future. Its effect is not just on the spouses and family as a unit but also on the entire society since the family is a micro society and the society bears whatever the family produces, family being the bedrock of society.

Safeguarding the society requires intentional and deliberate interventions at enhancing to preserve the family life irrespective of the demands that comes with work. Family preservation is almost directly proportional to time invested in the family (Osofsky and Fitzgerald, 2000) and not amount of money spent on it. The realization of this was a major benefit reported by the interview participants. All respondent agreed to the fact that the lockdown afforded them ample opportunity to connect strongly with their family despite the pressure of work and the challenge of working from home. A respondent reported: 
What I have learnt from the work-family experience based on the covid-19 pandemic is that there was previously no time for family interactions. We (referring to his family) are having all the time now. There is no barrier because you (referring to himself) are available to them every single time. (Husband, Oil and Gas service, 4 years of marriage)

The possible danger of work to the family life is once again exposed. The respondent who can still be considered young in the married life already viewed work as a barrier to familial interaction. However, the pandemic which brough about a forced lockdown gifted him opportunity to share valuable time with family, a thing that he had missed so much. Similarly, another respondent, who was the youngest in the marital life experience, also viewed the lockdown in same light. She noted that she and her husband saw the lockdown period as an opportunity to share more time together by staying home, helping them to bond more as a family. Thereby, "spend time and enjoy activities together as a family" (Wife, Educational Administration, 1 year of marriage). Such disposition is considered the best medicine for rejuvenating love and oneness in the marital life. Thus, the lockdown provided couples an opportunity to examine and reconsider their past decisions on matters relating to the family life.

The importance of spending quality time together as a family cannot be overemphasized. The joy that comes with it is enormous and strengthens family bond. To facilitate this, spouses must be very sensitive to the needs of their partner and child(ren) to avert psychological stress (anxiety and sadness) to keep family members in good shape emotionally and socially (UNICEF, 2020). Thus, spouses are to be; patient and understanding, engage their children in creative interactive activities and help children find positive ways to express disturbing feelings such as anger, fear and sadness (UNICEF, 2020). Which is only possible if time is created for family members while working from home. Succinctly, respondents agree to the need to have quality time with children as they have come to the recognition that:

It was necessary for spouse to; create time for family members (referring to partner and children), find moment to listen to the children. And having a sense of right judgement when they (referring to children) come to you for something. (Husband, Secondary school teacher, 6 years of marriage)

Here is implicated the responsibility shouldered on spouses in childcare which cannot be carried out by outsiders on their behalf, as it means they might never have the slightest idea of what or who their spouse or children are or have grown to become. Meaning that while working either from home or away from home, spouses must create time for family. This must be done collaboratively in other to achieve maximum benefit. This position was corroborated by the respondents,

We (couples) should be more patient. Get into a routine. Have time for everything (both work and family). We (couples, husband and wife) have to work and attend to the children at the same time. We (couples) have to put the most 
important thing first (referring to family) and the other things next. (Wife, Oil and Gas service, 6 years of marriage)

In line with the above, respondents generally considered the family as an essential part of the life of every individual. A respondent believed that her survival of the lockdown was because of the good relationship she enjoys with her spouse and children. She imagined what the situation would have been if the relationship with her family were sour. Thus, the recognition of the importance of maintaining a happy home, made the respondent below express explicitly her joy having made the right decision of putting her family above every other thing prior to the pandemic. She stated:

Family is key. I imagine if I had not had a good relationship with my husband and my children before now, it wouldn't be nice now staying with them at home all day long without having to go out. Moreover, if a woman is in an abusive marriage or relationship, it would not be too good for such a woman now. So, family is key. Love is paramount in any relationship. With this pandemic, $P$ ve learnt to prioritize my family above any other thing. (Wife, Media, 7 years of marriage)

This implicates the danger of the lockdown for troubled families; for instance, families where couples have lost marital bliss and are devoid of mutual understanding and love. A family of which intimate relationship is characterised by aggression, causing both physical and psychological torture to couples or children. Couples in such marriages would face high chance of serial abuse in a time of lockdown where they spend their entire day together, enclosed, isolated, away from the knowledge of others. In conversations, disagreement would arise, accusations and counter accusations; aggression sets in and then the possibility of violent physical exchange is almost certain. Couples battle economic and employment vulnerability as additional risk factors COVID-19 itself and the attendant challenges in the family life (Lebow, 2020). This explains the prevalence of domestic violence all over the world during the COVID-19 pandemic (Taub, 2020). Couples that desire saving their marriages or ignorantly relegated family life because of the demands of work life had time to reflect on their past actions and motivations. Thus, spouses' realization of their weaknesses in spousal and family care gave room for an immediate and conscious turn around.

Couples seemed to agree on the fact that the COVID-19-induced lockdown became a tool for family renewal in a unique way that many never expected. This means that the lockdown provided ample opportunity for many couples to actively and consciously improve their relationship, in a society where every individual is busy, with lack of time to rekindle their marriage (Stanley and Markman, 2020). Stanley and Markman (2020) highlighted the efforts that couples made to strengthen their bond and relationship and child care during the pandemic. These included: applying therapy to drill their parenting skills, brainstorming list of things that could increase their time together and fun as well as holding hands while watching a show or expressing appreciation and gratitude 
each night. Thus, the lockdown for couples, was a remarkable time for deep reflection and reconciliation of differences, giving spouses the opportunity to strategize for future adaptation. This was important, given the drastic changes that would impact every facet of the human life.

In line with this, Rivett (2020) opined that social interaction, recreation, work and family life will all be different after the experience of COVID-19 pandemic. Since the future will most likely see changes, it was only right to consider necessary adjustment to work-family life. An adjustment that will pave way for improvement in family relationship with an impact on work despite the complexity. Such would be possible if spouses work unitedly for same goal and then, organizations consider family protection as a key part of organizational growth. Organizations also need to adopt relevant policies and provide necessary facilities and infrastructure that would make work both productive and progressive, especially for times when workers would need to work from home. According to a respondent,

It is high time organizations start looking in that direction. Nobody saw this coming. We don't have to get to certain situations before we start making arrangement before then. For instance, people who never thought it was important to have a laptop or internet connection now see the need. Some people didn't have tools to work remotely. (Husband, Copy writer, 10 years of marriage)

The occurrence of COVID-19 and the attendant lockdown opened people's minds to certain imperatives of a harmonious and happy work and family life that had been previously neglected. Today, it is generally agreed that remote work is the way to go (Rivett, 2020). The above excerpt further suggests that online programs as future adaptive measure that would lessen the complexity of work and family life. Through online platforms like skype and zoom couples can enjoy the feeling of closeness and assess wellness of their partner and other family members while working away from home. Online platforms would also give couples a lifeline to enjoy family presence as they could interact actively with work schedules while working from home. Hence affording couples the opportunity of enjoying quality time with partner and family members for a blissful marriage.

\section{Conclusion}

This study examined the work-family experience before, during and after the COVID-19 pandemic lockdown. It revealed that work-life harmony, desirable as it is, seemed impracticable in a Nigerian city with high socio-economic activity amidst myriads of physical stress and mental strains, like Lagos. Beyond the conventional work-life integration (WLI) approaches like scheduling, prioritizing, time management and so forth, there is need to develop more practicable frameworks that can enhance WLI. In fact, studies have continually shown that demanding jobs, economic hardship and disasters threatens couples' marital bliss (Pietromonaco and Overall, 2020). Thus, the needs to initiate policies that 
are work-family friendly to ensure economic sustenance and social preservation and protection of family life. Policies that will provide room for couples to work and still have time for family in other to build a sane and dependable society.

The necessity and value of having quality time with family members especially between spouses is intriguing. Quality time between spouses and their family can change a lot on the nature of relationship existent in a family at a particular time; of which the time of the lockdown is not excused. Lewandowski's (2020) study that sought to address "If couples felt the pandemic would ruin their relationship" reported positive change in couples' relationship during the lockdown. After spending time with partners because of the forced lockdown order, couples felt more attached to their partners than in those times when they spent little/ limited time. Thus, the negative impact of the work life on the family life is further exposed. Though, the work life becomes an obstacle to the family life only when the demands of work are not properly managed.

Appropriate ways of managing the demands of work while working from home was addressed. It was revealed that for efficiency and productivity in meeting organizational targets and demands while working from home, facilities such as laptop and strong internet service need be considered. These could be made available to workers by the organization or organization creates easy channels for workers to possess such themselves with little or no pressure in preparation for future challenges. A conducive environment that would ensure maximum focus while working from home would also need to be provided by spouses so as to manage distractions.

From this study, it has been successfully established that it is possible to enjoy a successful and fruitful work-family life while working, either at or away from home. Attention of spouses have been drawn to the necessity of setting priorities right; making out time for family irrespective of work demands. The study provides exposition to the challenges that spouses encountered during the lockdown period while working from home and the coping strategies to help spouses live through the challenges productively. Also examined was organizational roles in ensuring workers were provided with needed resources to meet the challenges of the changing times. Thus, the lockdown experience that brought about the work from home policy has left us with lots of positives for future adaptability.

\section{Recommendations}

In spite of its capacity to improve socio-economic conditions and similar other benefits, dual earnership is not without consequences for married couples. The complexity of the work-family interfaces require flexibility as well as adequate understanding of WLI principles to stand live life in its fullness and be happy, especially in a busy socio-economic mega city like Lagos. This would cushion the effects of eventualities, preserve and enhance family bond and help negotiate life stressors such as confronted humanity during the pandemic. The following recommendations are proposed for smooth adaptability to safeguard family rela- 
tionship in a home where couples are dual earners.

1) Quality relationship among couples and within the entire family is necessary to successfully navigate through different times in life; both the thick and thin.

2) Couples must make out time for each other irrespective of work demands in other to build a happy family. Family is central to having a good and happy society hence, the need to uphold family bond and friendship. To increase marital friendship, couples are encouraged to develop the habit of getting-together daily, spending hours of their day intimately.

3) Organisations need to prioritise family life and good intimate relationships in their structure by making policies that support/ improve family bonding e.g. compulsory annual leave, couples' dinner, family get together etc.

4) Participation in formative family life programs like the family advisory system, regular retreat and recreation with spouse are necessary to ease-out stress for dual earner couples. This will enable the couples to better manage time and family, realize the dignity of family life and the need for each to develop quality relationships with their spouse.

5) There is no alternative to spending quality time with partner and child(ren). This is indispensable to nurturing quality relationship in family.

6) To ensure maintenance of stable healthy relationship, partners must be sensitive to the dangers that could undermine having blissful home. These include demanding jobs, economic hardship and disasters in any form (Pietromonaco and Overall, 2020). Knowledge of this will guide their making right decisions when faced with tough situations that endangers wellness of their relationship.

7) Couples need not be too busy with work or allow themselves to be overwhelmed by the demands of work that they become insensitive to the needs of family as this could have great consequence on family cordiality and capable of causing family unrest.

8) Hanging out with spouse deliberately is great medicine for the soul and body. It eases stress and the pressure of work and greases couples romantic and intimate relationship for a flourishing marriage.

9) There is the need for government to provide national ambience through infrastructure and facilities that support family life.

10) There is also the need for employers to better engage their workers for improved productivity without taking unnecessary toll on employee marriage and family life.

11) Married couples also need to carefully study and understand the uniqueness of their family and spouses vis-à-vis the peculiarity of their work-family situation and the nature of demand in both ends.

12) Organisations have a critical role to play in equipping their workers with the skills to master the art of work-life integration, through training, while also adopting family-friendly policies for better employee engagement, improved 
productivity and job satisfaction.

13) Couples should have a special room in their home that would create quality ambience to work from home where necessary. This would ensure focus and achievement of needed effectiveness in meeting work demands.

14) Couples need to be creative in renewing the bond of love within the family. Creating conducive environment and contexts for relaxation, discussion, joke and play will improve the understanding between spouses and between spouses and their children. Depending on the affordance of the couples, a conducive environment is not only limited to physical space and facilities, but also to the quality of relationships engendered by the couple.

15) Organisations need to initiate department that would handle sensitive issues like workers welfare and disaster management.

\section{Conflicts of Interest}

The authors declare no conflicts of interest regarding the publication of this paper.

\section{References}

Ghosh, R., Dubey, M. J., Chatter, S., \& Dubey, S. (2020). Impact of COVID-19 on Children: Special Focus on the Psychosocial Aspect. Minerva Pediatrics, 72, 226-235.

Kasa, M., \& Hassan, Z. (2017). Burnout-Dimensions with Work-Family Conflict among Hotel Employees: Flow Experience as Mediating Role. Journal of Management and Marketing Review, 2, 1-7.

Lebow, J. L. (2020). Family in the Age of COVID-19. Family Process, 59, 1-4. https://www.researchgate.net/publication/341427901 Family in the Age of COVID-19

Lewandowski, G. (2020). Will the Pandemic Ruin Your Relationship? https://www.psychologytoday.com/us/blog/the-psychology-relationships/202005/will-t he-pandemic-ruin-your-relationship

Ojewale, L. Y. (2020). Psychological State and Family Functioning of University of Ibadan Students during the COVID-19 Lockdown.

https://www.medrxiv.org/content/10.1101/2020.07.09.20149997v1

Organisation for Economic Co-operation and Development (OECD) (2008). OECD Information Technology Outlook 2008, Paris. https://www.oecd.org/sti/ieconomy/41895578.pdf

Osofsky, J. D, \& Fitzgerald, H. E. (2000). WAIMH Handbook of Infant Mental Health, Perspectives on Infant Mental Health. Wiley. https://www.wiley.com/en-us/WAIMH+Handbook+of+Infant+Mental+Health\%2C+V olume $+1 \% 2 \mathrm{C}+$ Perspectives+on+Infant+Mental+Health-p-9780471189411

Pietromonaco, P. R., \& Overall, N. C. (2020). Applying Relationship Science to Evaluate How the COVID-19 Pandemic May Impact Couples' Relationships. American Psychologist. https://psycnet.apa.org/fulltext/2020-54105-001.html

Rivett, M. (2020). Relational Lockdown and Relational Trauma in the Time of Coronavirus: A Reflection from a UK Family Therapist. Family Process, 59, 1-10.

https://www.researchgate.net/publication/342496662 Relational Lockdown and Relation al Trauma in the Time of Coronavirus A Reflection from a UK Family Therapist

Stanley, S. M., \& Markman, H. J. (2020). Helping Couples in the Shadow of COVID-19. 
Family Process, 59, 937-955.

Taub, A. (2020). A New COVID-19 Crisis: Domestic Abuse Rises Worldwide. New York Times.

https://www.nytimes.com/2020/04/06/world/coronavirus-domestic-violence.html

UNICEF (2020). Psychosocial Support for Children during COVID-19. A Manual for Parents and Caregivers.

https://www.unicef.org/india/media/3401/file/PSS-COVID19-Manual-ChildLine.pdf

United Nations Office for Drug and Crime (UNODC) (2020). Information on Parenting during COVID-19. Central America and the Caribbean.

https://www.unodc.org/ropan/en/information-on-parenting-during-covid-19.html 